\title{
Introducing Supergrids, Superblocks, Areas, Networks, and Levels to Urban Morphological Analyses
}

Anne Vernez Moudon*

\begin{abstract}
Urban morphological analyses have identified the parcel (plot), the building type, or the plan unit (tessuto in Italian) as the basic elements of urban form. As cities have grown in geographic size disproportionately to their growth in population over the past seven decades, new elements have been introduced that structure their form. This essay describes these new elements and proposes that they be formally recognized in urban morphology. It introduces a conceptual framework for a multilevel structure of urban space using areas and networks and including supergrids and superblocks to guide morphological analyses.
\end{abstract}

Keywords: Morphological elements; a posteriori approach; a priori approach.

* Dr es Sc, Professor Emerita of Architecture, Landscape Architecture, and Urban Design and Planning, Adjunct Professor of Epidemiology and Civil and Environmental Engineering Director, Urban Form Lab ORCID

Email:moudon@uw.edu 


\section{INTRODUCTION}

The foundational concepts and frameworks used in urban morphology date from the mid-20th century, a time when cities were, by today's standards, small or even very small. So far, urban morphological analyses have focused primarily on the parcel (plot in British English), the building type, or the plan unit (tessuto in Italian), an approach that suggests studying urban form from the ground up. This approach remains entirely valid today since cities indeed continue to emerge building by building, from the ground up. However, cities have grown in size over the past seven decades and new elements have been introduced that structure their form. This essay describes these new elements and proposes that they be formally recognized and inserted into analytic methods used in urban morphology.

\section{FUNDAMENTALS OF URBAN MORPHOLOGICAL RESEARCH}

Urban morphological analysis rests on three elements: the building and its parcel (plot), the street and the city block, and the plan unit (tessuto) (Whitehand 1981, Moudon 1997, Scheer 2015, Scheer 2018). Different studies give different emphases to the different elements. Some focus on building without addressing the concurrent parcel, either because the parcel has the same size and shape as the building footprint, or because the parcel contains many different buildings; other studies concentrate on the plan unit or tessuto. Again, it is entirely valid to study any or all of the elements of urban form in order to focus on different issues and to reflect on different problematics. However, it is essential to take into account how urban form elements relate to each other in order to fully consider their characteristics. This is because urban form elements are nested: buildings are contained in city blocks, and city blocks are nested in plan units. The characteristic of nestedness places elements at different levels. Recognizing levels of nesting in urban form is conceptually simple, save some nuances that are worth addressing.

\section{Caveat 1: Nesting is not scaling}

Nested forms suggest scales-with small elements contained into larger ones, or, conversely, large elements containing smaller ones. However, scale and scaling are words that should be used carefully, especially so that they are currently fashionable and overused in the tech world. The words give rise to multiple quandaries. First, scale and scaling connote measures and measuring; in the case of urban form elements, it has not been possible to use a consistent, standardized measure to distinguish between a building, a city block, and a plan unit-words and graphics are needed to "measure" building, city blocks, etc. Hence 
it seems more fitting to conceive of these elements as being at different levels, rather than at different scales. Second, scaling elements of physical space is done differently by different disciplines, creating confusion. Geographers refer to the representation of buildings as looking at the "large scale"; planners refer to the same as looking at the "small scale." Indeed, geographers are scaling elements based on the ratio of objects as measured on a map to their distance from the earth surface, with $1 / 1$ map scale being actual scale, and $1 / 100$ map scale being where one map unit equals $100^{\text {th }}$ of its actual size, as if it were 100 units away from the surface of earth. Hence maps depicting buildings are at a large scale because the buildings are mapped as being closer to the earth surface than would be the case of the map of an entire region. On the other hand, planners, as do engineers, use human perception to measure space, with buildings being small compared to an entire city or earth itself. Combining geographers and planners understanding of scale leads to two counterintuitive constructs that Hartshorn (1980, 8) characterized as "(1) large-scale or micro studies that involve a physically small study area, and (2) small-scale or macro studies that cover a very large physical area." Hartshorn being a geographer characterizes scale as it related to mapping and refers to levels as levels of abstraction (small-scale macro studies being more abstract than large-scale micro studies). Of note also, geographers use standard and precise measures of distance, while planners do not use engineers' precise measures of scale (e.g. macro scale representing "something large enough to be observed by the naked eye," and measured as $10^{-3}$ of a specified unit). And neither do planners formally label levels in urban space. Third, scaling is difficult to distinguish from sizing. Take for example a small building which is one of many on a street-block and compare it with a large building that covers an entire street-block. It can be said that the large building has been "scaled up," but it is useful to precise that in fact it has been both sized up and leveled up (since it now is at the same level as the street-block). Finally, and perhaps ironically, analyses using geographic information systems (GIS) are now "scaleless" because the tool can generate maps at almost "any" scale. GIS data is characterized with two scalar elements, the spatial extent of the data (e.g. an entire city) and the resolution or smallest spatial unit at which the data are available (e.g. street segment, building parcel, etc.)

\section{Caveat 2: Nesting is not layering}

The nesting of urban form elements is different from the layering of urban form. Layering refers to the characteristics of form that are grounded on the surface of earth -going down to below ground as well as up to above ground. Layering is what could be 
termed an a-posteriori, geological approach to urban form, serving to describe "what is" in a post-facto one-time snapshot and necessarily static state (Figures $1 \& 2$ ). The approach can be contrasted with what could be termed an a priori developmental or operational approach, which recognizes the nestedness of urban form elements; it addresses the processes by which cities are built and their dynamic state of change (Figure $3 \& 4$ ).

Figure 1. Use of layers for $a$ posteriori urban morphological analysis: M.R.G. Conzen fundamental elements of the town plan, streets, streets and plots, streets, plots, and buildings

Source: Whitehand, J.W.R. ed. (1981). The urban landscape, Historical development and management. Papers by MRG Conzen. In Institute of British Geographers, Special Publications 13, 26.

Figure 2. Use of layers for $a$ posteriori "geological" approach to morphological analysis: B.C. Scheer spatio-temporal hierarchy introducing the element of time into urban morphological analysis.

Source: Scheer B.C. (2001) The anatomy of Sprawl. Places 14(2), 30.
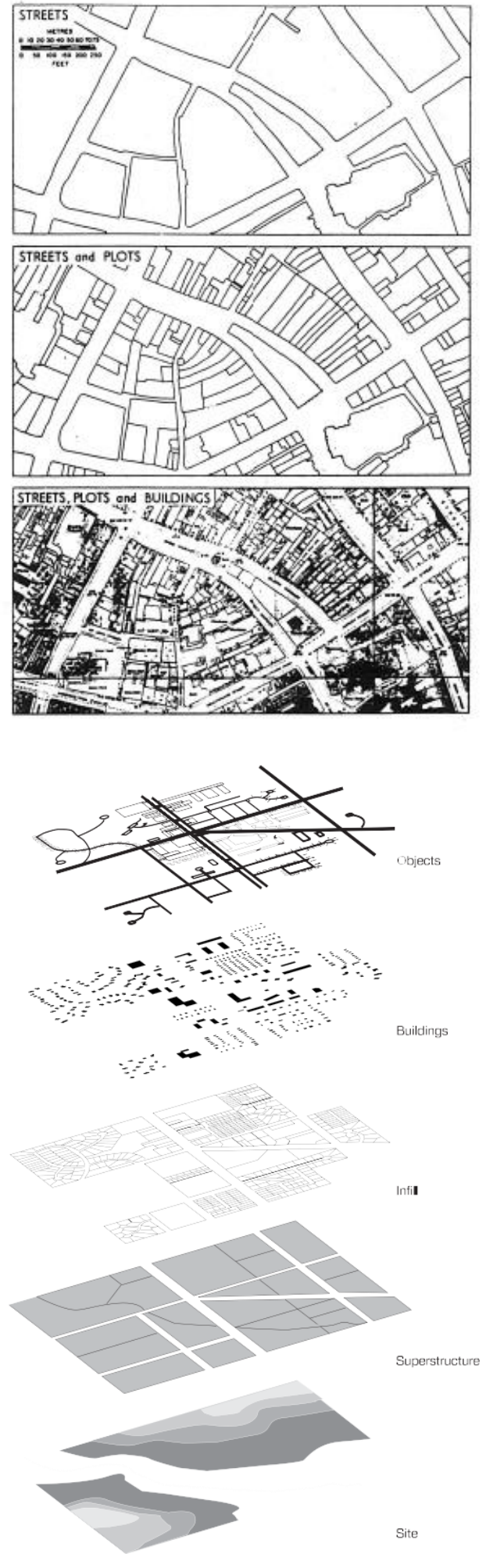

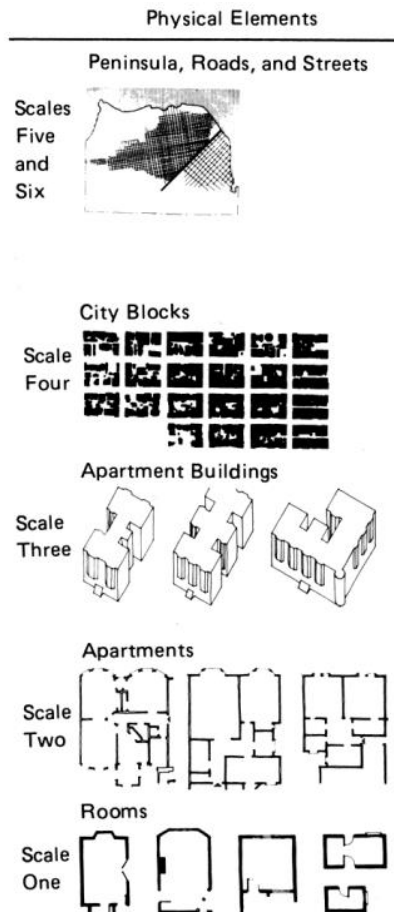

단
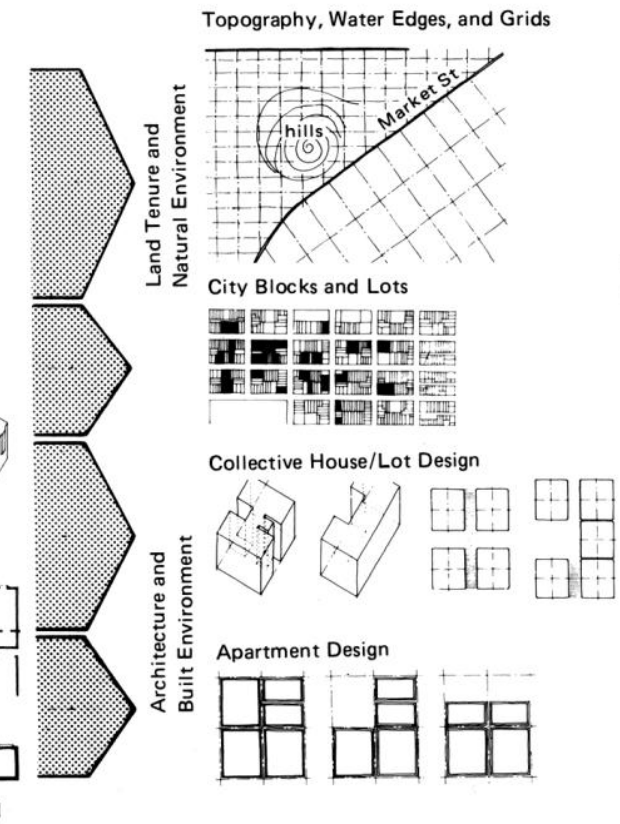

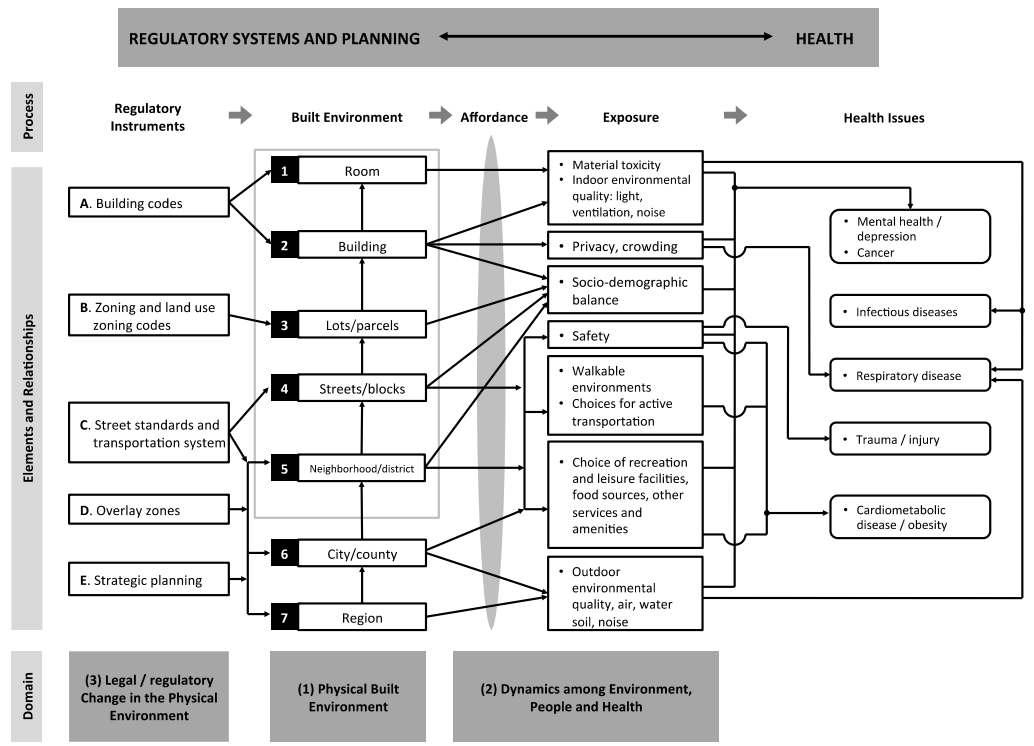

In sum, the fundamentals of urban morphological research have consisted of three elements that are nested and define three core levels: buildings, street-blocks, and plan units. To wit, however, urban morphological research can stretch beyond the three core levels, that is it can either focus "down" within buildings or it can go "up" beyond plan units: rooms and corridors are nested in buildings just as plan units are nested into neighborhoods, districts, towns, or cities (Berke \& Moudon, 2014). The multilevelness of urban form parallels that of societal structures (the well-understood social structure that spans from individuals to

Figure 3. A priori multilevel structure of urban space with nested elements: a "developmental or operational" approach to city building, the case of San Francisco, 1920s. (Note the use of the term "scale" which, some 30 years later, I suggest is not appropriate and should be changed to "levels").

Source: Moudon A.V. (1986a) Built for change, Neighborhood architecture in San Francisco. Cambridge MA: The MIT Press, 124.

Figure 4. A priori multilevel structure of urban space with nested elements: theoretical structure of built environment change (BEC) for use in health research.

Source: Berke E.M., Vernez-Moudon A. (2014). Built environment change: A framework to support healthenhancing behaviour through environmental policy and health research. Journal of Epidemiology and Community Health, 68(6), 588. 
groups) and as such, is essential to consider in the conceptual framework of urban morphological analysis.

\section{LARGER ELEMENTS, LARGER CITIES}

Based on its current fundamentals, urban morphological research can be challenging when applied to contemporary cities. This is because city building practices over the past half century have introduced major changes in the characteristics of the three basic elements and in how they relate to and nest with each other.

Most flagrantly observed is the unprecedented increase in the size of buildings over the past century. In middle-income countries and up, even the most modest houses are much larger now than they were a few decades ago for corresponding income or status level. The average residential unit size in Hong Kong has grown fourfold, from 3 to $12 \mathrm{~m}^{2}$ per person since the 1960s. Even more obvious is the increase in the size of commercial and institutional buildings-as illustrated for example in the $2017120,000 \mathrm{~m}^{2}$ Paris Tribunal or the 1988 225,000 m² Ministry of the Economy and Finance buildings in Paris, France. And Paris has smaller institutional buildings than Dubai, Tokyo, or $1^{\text {st }}$ and $2^{\text {nd }}$ tier cities in China-Tokyo Metropolitan Government 1990 building has $196,000 \mathrm{~m}^{2}$. The change in building size affects the relationship between buildings and street-blocks as larger buildings nest differently within street-blocks than small buildings.

Parcels have grown in size as well. For single-family housing development patterns, average parcel size has grown pretty much in proportion to the change in building (house) size (Chow, 2002). But for multi-family, commercial, and institutional development, parcel size has often increased independently from the size of buildings. For example, in North American suburban apartment development, the buildings themselves remain relatively small; they are two- or three-story structures with a central stairwell serving two to four units per floor. Yet these structures now often sit as a group on large parcels that correspond to the size of multiple traditional street-blocks. For commercial development, and for retail uses particularly, parcel size has grown from hosting single to multiple buildings, as is the case of shopping malls.

Increases in parcel size are the result of the aggregation of private wealth or greater public control over urban land: large companies, pension funds, insurance companies, labor unions, etc., now own large multi-family and commercial developments. In some economies, public entities also retain land rights in family-owned condominiums (as is the case in China and some European cities). Notably, in Chinese cities where land remains in public or 
collective ownership, de facto parcels mark territories controlled by one management entity that to all intents and purposes acts as a landowner, while residents or commercial entities occupying the parcel act as the co-owners of individual or parts of buildings with their immediate surrounding open space.

Changes in parcel size affect the relationship with and between buildings and with street-blocks. These changes have been documented. Focusing on Paris in the late $19^{\text {th }}$ century, Panerai and colleagues (1977) analyzed the pre-modern consolidation of medieval street-blocks into planned block-sized developments, leading to the increase in the size of what Conzen called plan units (Panerai, Castex, \& Depaule, 1977). For the $20^{\text {th }}$ century, the case of San Francisco showed the disintegration of the individual parcel hosting row- and semi-detached houses or apartments, also leading to the increase in the size of the plan unit (Moudon, 1986a, 128).

Still, the increases in the sizes of either buildings or parcels pale in comparison to the increases in the size of cities themselves over the past seven decades. Worldwide, cities have grown in size as the result of the combination of population growth and the increase in the urbanization rates of the world population. The impacts of population growth and urbanization on urban form are multiple. The Seattle region conurbation experienced a 5 -fold increase in its built-up area (now at 2,500 $\mathrm{km}^{2}$ ), against a 3 -fold increase in population since the 1960s (now at 3.4 million). A 3.5fold increase in Shanghai Municipality's built up area took place in only two decades (1990-2010) (Yin, Yin, Zhong, Xu, Hu, Wang, \& $\mathrm{Wu}, 2011)$. Yet while most cities have grown in population and built up areas, there are great variations in urban forms. As an example, the 25 million Shanghainese live in half of the area where 11 million New Yorkers live, and thus at densities that are more than four times their counterparts in North America's densest city.

\section{NEW PROBLEMATIC}

The growth in the size of city-region agglomerations has engendered two aspects of a problematic that affects the structure of urban form. One is the need for intra-city mobility in order to accommodate significant increases in the distances that separate urban activities. The Roman city of Florence could be traversed on foot in less than one hour, and Paris intra-muros could be traveled between east and west in about double that time up to the $18^{\text {th }}$ century. In contrast, traversing most of contemporary cities on foot today would take a good part of a day and more! Higher-speed transport has had to come to the rescue and to shorten within-city distances so urbanites could frequently visit different areas of the 
expanded city. Horse-drawn conveyances first offered higherspeed travel, but they, and traditional city streets, failed to serve efficiently the large numbers of urbanites needing to travel the longer distances between activities in the same city. Motorized transport had to eventually be introduced to address the new urban mobility needs. In turn, new modes of transport had to be supported by new, large, city-wide infrastructure elements.

Second, large cities have demanded new ways to be conceptualized in order to structure their planning and their management. The term neighborhood captured a new planning concept that encapsulated the discrete part of a large city, giving it definable social, economic, geographic, and physical characteristics. The idea of neighborhood is said to be a British creation of the late $19^{\text {th }}$ century (Smailes 1968), thought to be the basic structural element of increasingly large cities. Clarence Perry's Neighborhood Unit (1929) is perhaps best known as a conceptual model of neighborhood. However, an increasing amount of research is documenting similar early $20^{\text {th }}$ century neighborhood models developed in China, Japan, and the Soviet Union (Peponis, Park, \& Feng, 2016, Chen 2017). In all cases, the neighborhood came to be considered as the building block of the modern city.

City-wide mobility-serving infrastructure and neighborhoods introduce new dimensions to urban morphology analyses.

\section{MOBILITY - SERVING INFRASTRUCTURE AND NEIGHBORHOODS}

City-wide infrastructures are not new (Panerai, Depaule, \& Demorgon, 1999, 139). They existed long ago in major cities not for mobility but for bringing in vital water in the form of aqueducts, and for defense, as fortifications and canals. The most well-known, and perhaps earliest, attempt at building infrastructures to improve intra-city mobility was Baron Haussmann's restructure of Paris surface transport and utilities. With the scheme of boldly carving boulevards within the medieval city fabric, he introduced new mobility-serving morphological elements at the city level. In vogue in the second half of the $19^{\text {th }}$ century, urban restructuration schemes similar to Paris's were carried out in many of the major European and Middle Eastern cities that were suffering from overcrowding and needed expansion (Sarraf 2010). Today, the subways and motorways that used to be the privilege of capital cities until the early $20^{\text {th }}$ century have become ubiquitous higher-speed transport infrastructure that serve most cities and city-regions with more than 1 million population in middle- and upper-income countries. 
For neighborhoods, a shared set of principles guides the definition of neighborhood models. Unlike its precedent, the quarter (quartier, quartiere, barrio), which was defined by its commercial use, the early $20^{\text {th }}$ century neighborhood (term coming from "to be near, vecindad, or voisinage") is conceived as a place of residence. Housing is the neighborhood dominant land use, which is complemented by nearby services to meet daily or weekly needs. Travel within the neighborhood is slow and safe, with motorized traffic either tamed or eliminated. Higher-speed travel is accommodated on arterial streets delineating the neighborhood boundaries. These arterials are in turn lined by higher density housing (apartments) and stores. The neighborhood center itself consists of different land uses, depending on the model. Perry's early model put schools, community centers, and parks as central neighborhood services. New urbanists in the USA and Chinese planners located shops, schools, transit, and parks in the center (Duany \& Plater-Zyberk, 1991). Neighborhood units vary in size from $400 \mathrm{~m}$ to $500 \mathrm{~m}$ square depending on the model. Units are often paired in order to share commercial land uses. There seems to be agreement that commercial facilities need to serve a minimum area contained within a $400 \mathrm{~m}$ buffer and equivalent to $800 \mathrm{~m}$ square (Figure 5).
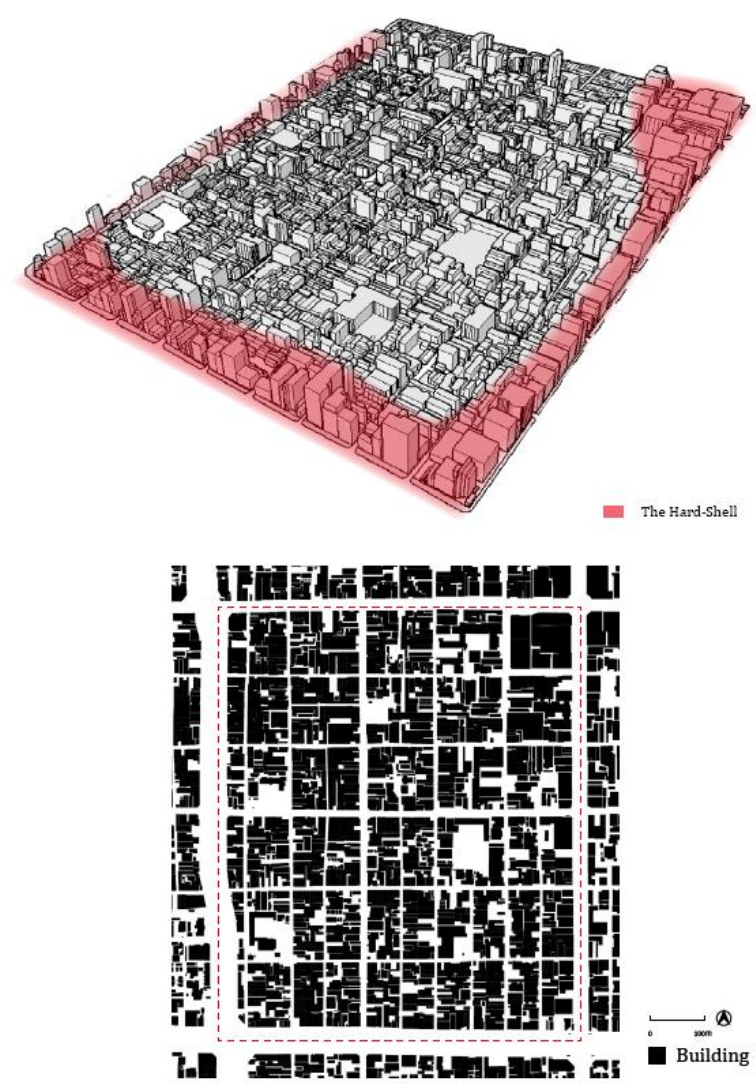

All neighborhood unit models organize streets hierarchically. The unit is contained within streets where travel occurs at higher
Figure 5. Shijo-Karasuma superblock in Kyoto's supergrid. Top: 3D model of "hard shell-soft yolk" form of superblock. Bottom: Figure ground.

Source: Chen, X. (2017). A comparative study of supergrid and superblock urban structure in China and Japan, Rethinking the Chinese superblocks: Learning from Japanese experience. Doctor of Philosophy thesis, Faculty of Architecture, Design \& Planning, The University of Sydney, Australia, C6.9 
speed, while its core is served by narrower, lower speed streets and pedestrian paths. The neighborhood unit is thus a hybrid concept, encompassing both areas for dwelling and networks for mobility. The networks containing the neighborhood area operate at the inter-neighborhood or inter-district level, in contrast to slower-speed city streets that function at the intra-neighborhood level.

Given the nestedness of urban space, the inter-neighborhood networks become intra-city networks. The resulting intra-city transport infrastructure can be star-shaped-like networks of Haussmann's Paris, irregular as in turn of the 20 th century subways lines, or grid-like as in Detroit's or Los Angeles's freeways.

\section{THE NEW DUALITY OF AREAS AND NETWORKS}

Mobility as a new aspect of contemporary cities was concisely captured by Gabriel Dupuy in his book L'urbanisme des réseaux (1991). He demonstrated how citywide, intra-city réseaux or networks have become important elements shaping the form of today's large cities. Recognizing their existence requires adding to the way urban morphologists have looked at cities. So far, urban morphologists have offered a primarily area-based approach related to understanding the traditional and relatively small city. They have focused on documenting the places where humans dwell; where space is used for living, working, and recreating. Buildings, street-blocks and plan units allow one to understand the city as territory for habitation, commerce, religion and other activities. Of course, locomotion being an intrinsic human characteristic, moving between dwells and activities was and has always been necessary. Urban morphologists have considered networks before, either in the form of corridors within buildings, or as streets providing access to parcels and buildings along block faces. To wit, M.R.G. Conzen was keenly aware of the duality between areas and networks, as attested by his neologism, the street-block. The word street-block magically captures the essence of urban space, which lies at the intersection of dwellinginhabiting and moving-accessing; and of more private versus more public spaces. (Unfortunately, the term street-block cannot be easily translated into Romance languages). In another example of recognizing the duality of areas and networks, Cerdà had incorporated the idea of mobility and networks in the physical shape of Barcelona's Ensanche's blocks: those were chamfered, ostensibly to better accommodate directional change in movement patterns. 
Further, theories of neighborhood, which tacitly or explicitly heralded the concept of the superblock, suggested that morphologically speaking, the neighborhood was to be conceived of as a higher-level Conzenian street-block. A possible name for the neighborhood as a hybrid element defining both an area and a network, would be a hyphenated appellation superstreetneighborhoodblock. These terms may be unduly complicated, and a simpler alternative could be superstreet-block, which would build on Conzen's nomenclature. For this publication, I selected combining a more familiar set of terms, supergrid-superblock, which Chen (2017) and others have used. Of note, however, the term grid does not only apply to orthogonal geometries, just like the term block does not imply orthogonality.

\section{Caveat 3: A neighborhood is not a plan unit}

The concept of neighborhood is similar to, but not synonymous with M.R.G. Conzen's plan unit. The plan unit is an area of a town that was planned and/or built as one spatial unit and that, as a result of this planning, contained similar building and street-block types. As such, the plan unit is a conceptual tool to capture post facto a city area's development characteristics. Distinctively, a neighborhood is an a priori urban planning and social concept. A neighborhood can be physically developed in different phases and have multiple building or street-block types, and therefore can be made of what would be considered several plan units. Therefore, while the plan unit and the neighborhood are both above the street-block in urban morphological analysis, they are at different levels.

\section{N.B. Speed of movement, mobility versus accessibility}

The concept of mobility necessarily exist at different levels. There is a micro and a macro dimension to urban mobility, just like there is a micro and a macro urban morphology (Moudon, 2002). The emergence of macro-level mobility in the form of intra-city motorized transport systems was gradual as the need for longer distance travel was being felt while cities grew in size. A multidistrict hierarchy of streets eventually emerged to accommodate different speeds of travel, slow at the micro level and faster at the macro level. Further, transport planners distinguish between mobility and accessibility (Handy, 2002). To illustrate these dichotomies, travel on subways or motorways covers longer distances or is of longer duration than travel by foot or by twowheeler; as a result, subway or motorway networks are of lower density than that of city streets, and have fewer intersections (for choice in directional change) and fewer access points per arial unit (in and out ramps for motorways; stations for subways) than networks used for walking or cycling for which access takes the 
form of doorways into buildings or entry points into facilities contained with a city block for city streets.

Intra-city, inter-neighborhood motorized transport systems introduce a new level of urban space, one above that of the plan unit, within which plan units become nested.

\section{CONCLUDING WITH NEW ELEMENTS AND NEW LEVELS}

The size and form of contemporary cities and their elements have evolved over the past several decades, suggesting that changes be made to the theoretical and conceptual frameworks used to guide urban morphological analyses. First, the primarily area-based approach used in morphological analyses so far needs to be complemented by a network-based conceptualization of urban space. Mobility-serving elements of urban form (e.g. streets, thoroughfares, etc.) need to be considered both separately and together with the areas to which they provide access (e.g. parcels, blocks, etc.). Urban morphological analyses need recognize the dual function of urban space, which includes dwelling, occupying, inhabiting, as well as locomoting, traveling, circulating, etc., links settlement to movement, the two dimensions of urban space.

Second, a new, higher level of analysis is needed to capture the larger elements characterizing today's large cities. This new level is defined dually as an area, called superblocks, which is contained within a network, called supergrids.

Table 1. A priori multilevel structure of urban space using areas and networks and including supergrids and superblocks

\begin{tabular}{|c|c|c|c|c|c|c|c|}
\hline \multicolumn{3}{|c|}{ Accepted elements and levels } & \multicolumn{5}{|c|}{ Proposed elements and levels } \\
\hline & & & \multicolumn{2}{|c|}{ NETWORKS } & \multicolumn{3}{|c|}{ AREAS } \\
\hline \multirow{3}{*}{$\begin{array}{l}\text { nestedness } \\
\text { level } 1\end{array}$} & \multirow{3}{*}{$\begin{array}{l}\text { element } \\
\text { building }\end{array}$} & & hierarchy & element & nestedness & element & \\
\hline & & & micro & & level 0 & room & \\
\hline & & \multirow{2}{*}{ parcel/plot } & & & & & \\
\hline level 2 & street-block & & micro & corridor & level 1 & building & \multirow{3}{*}{ parcelplot } \\
\hline level 3 & plan unittessuto & & micro & street & level 2 & block & \\
\hline & & & macro & & level 3 & plan unittessuto & \\
\hline & & & macro & supergrid & level 4 & superblock & \\
\hline
\end{tabular}

Table 1 summarizes proposed changes in the morphological characterization of urban form. A level 4 is added to reflect intracity elements. Also added is a level 0 , for completeness, and to include the studies of the many morphologists who focus on the study of building types.

The parcel or plot is shown in the figure as the element that links buildings to city street-blocks in traditional cities. Since the early $20^{\text {th }}$ century, changes in urban land ownership patterns have contributed to increasing the size of many parcels such that they individually can cover one or more street-blocks. The change in 
the size of parcel is translated into the parcel spanning level 1 to beyond level 2 and into level 3.

The proposed new elements and levels sketch out a conceptual framework for use in urban morphological analyses. Table 1 can serve to place studies in the framework, according to the specific elements they focus on, and help identify appropriate levels that are standardized to facilitate comparison between studies.

\section{REFERENCES}

Berke, E.M., \& Vernez-Moudon, A. (2014) Built environment change: A framework to support health-enhancing behaviour through environmental policy and health research. Journal of Epidemiology and Community Health, 68(6), 586-590.

Chen, X. (2017). A comparative study of supergrid and superblock urban structure in China and Japan, Rethinking the Chinese superblocks: Learning from Japanese experience. Doctor of Philosophy thesis, Faculty of Architecture, Design \& Planning, The University of Sydney, Australia, http://hdl.handle.net/2123/17986

Chow, R.Y. (2002). Suburban Space: The Fabric of Dwelling. Berkeley, CA: University of California Press.

Duany, A., \& Plater-Zyberk, E. (1991) Towns and town-making principles. New York: Rizzoli

Dupuy, G. (1991). L'Urbanisme des réseaux : théories et méthodes. Paris: Armand Colin.

Handy, S. (2002). Accessibility- vs. mobility-enhancing strategies for addressing automobile dependence in the U.S. Paper prepared for the European Conference of Ministers of Transport, May, http://www.des.ucdavis.edu/faculty/han dy/ECMT_report.pdf

Hartshorn, T.R. (1980) Interpreting the city: An urban geography. New York: John Wiley \& Sons

Lu, D. (2006). Remaking Chinese urban form: Modernity, scarcity and space, 1949-2005. London: Routledge.

Moudon, A.V. (1986a). Built for change: Neighborhood architecture in San Francisco. Cambridge, MA: The MIT Press.

Moudon, A.V. (1986b). Platting versus planning: Housing at the household scale. Landscape 29, 30-38.

Moudon, A.V. (1997) Urban morphology as an emerging interdisciplinary field. Urban Morphology. 1, 3-10 http://www.urbanform.org/pdf/moudon1997.pdf

Moudon, A.V. (2002). Thinking about micro and macro urban morphology. Urban Morphology. 6(1), 37-39.

Panerai, Ph., Castex, J., Depaule, J.C., (1977). Formes urbaines, de l'îlot à la barre. Paris: Éditions Parenthèses. 
Panerai, Ph., Depaule, J.C., \& Demorgon, M. (1999). Analyse urbaine. Paris: Collection Eupalinos.

Peponis, J., Park, J., \& Feng, C. (2016) The city as interface of scales: Gangnam Urbanism. In S. H. Kim, E. Cinn, K. Ahn, S. Kim, I. Chung, D. E. Jeong, \& R. Enos. (Eds.), The FAR game. Seoul, Korea: SPACE Books, 102-111.

Perry, C. (1929). Neighborhood and community planning comprising three monographs: The Neighborhood Unit. New York, Regional Plan of New York and Its Environs.

Sarraf, M. (2010). Vestiges of urban spirit, Isfahan's urban fabric through socio-spatial transformations. Licentiate Thesis. KTH, Royal Institute of Technology, School of Architecture $\&$ the Built Environment, Stockholm.

Smailes, A.E. (1968 [1953]). The Geography of towns. Chicago: Aldine Publishing Company.

Scheer, B.C. (2001). The anatomy of Sprawl. Places 14(2), 28-37. https://placesjournal.org/assets/legacy/pdfs/theanatomy-of-sprawl.pdf?0574aa

Scheer, B.C. (2015). The epistemology of urban morphology. Urban Morphology 19, 117-134.

Scheer, B.C. (2018). Toward a minimalist definition of the plot. Urban Morphology 22, 162-163.

Yin, J., Yin, Z., Zhong, H., Xu, S., Hu, X., Wang, J., \& Wu, J. (2011). Monitoring urban expansion and land use/land cover changes of Shanghai Metropolitan Area during the Transitional Economy (1979-2009) in China. Environmental Monitoring and Assessment 177 (1-4), 609-621. https://doi.org/10.1007/s10661-010-1660-8.

Whitehand, J.W.R. (1981). The urban landscape, Historical development and management. Papers by MRG Conzen. In Institute of British Geographers, Special Publications 13.

\section{Resume}

While a Professor with the Department of Urban Design and Planning I instructed students in urban design and research methods. My work focuses on urban form analysis, land monitoring, neighborhood and street design, active travel and health. The National Institutes of Health and the US and Washington State departments of Transportation support current research on the built and social environments at the UFL. The research examines environmental influences on physical activity, active travel, eating behaviors, and other health outcomes. Done in close collaboration with colleagues in public health and transportation planning, the research is now based on high-resolution geospatial data on the built environment and objective behavior data. I collaborate with many colleagues, students, and organizations nationally and internationally. 